\title{
Hand tool handle design based on hand measurements
}

\author{
Ching-yi Wang ${ }^{1, a}$ and Deng-chuan Cai ${ }^{2}$ \\ ${ }^{1}$ Department of Industrial Design, Tatung University, Taipei City 104, Taiwan \\ ${ }^{2}$ National Yunlin University of Science and Technology, Douliou, Yunlin City 64002, Taiwan
}

\begin{abstract}
This study provides a tool handle design guideline based on measurements of hand gripping diameter. Anthropometric measurements on hands of 60 participants were collected with a caliper. The results in the current study concluded the guidelines for handle design, including: (1) a definition of handle design was depended on the users' hand length and hand breadth, (2) different gender would affect the size of tool handle, (3) the handle length at least should be $100 \mathrm{~mm}$, (4) the cross-section handle of elliptical shape was better for gripping, and (5) the best ratio of handle cross-section with width and length should be 1:1.25. These findings can serve as references for tool handle design, and improve comfort for users.
\end{abstract}

\section{Introduction}

Correct tool design is important for preventing upper-extremity musculoskeletal disorders. Considering the ergonomics of a hand-tool, in addition to its main function, the most important part is the tool's handle. Tool handle design research has been previously limited to the determination of the diameters of cylindrical handles to increase performance and comfort for reducing the chances of CTD (i.e., blisters, inflamed skin, cramped muscles, etc.) [1-4]. Many studies have researched the topic of tool handle design to define the optimal size and shape of a tool handle. Most of the studies have focused on cylindrical [5-7] or elliptical [8-9] shapes of the handles to provide guidelines for determining the optimal diameters to increase finger-force comfort, exertion, and the contact area. According to the previous studies on the related designs of the ergonomic handle, a hand tool design principles are summarized as following:

- Handle diameter: a grip design should consider the hand action when holding the grip [10]. A handle with a diameter of 30 to $40 \mathrm{~mm}$ is most suitable for a gun or electric tool [5]. Moreover, the handle suitable for both male and female was a cylindrical handle with a diameter of around $40 \mathrm{~cm}$ [8]. Some studies suggested that the handle diameter should be in a range of 30 to $45 \mathrm{~mm}$ [7]. However, some studies argued that the diameter should be in a range of 25 to $50 \mathrm{~mm}$ [6]. In addition, a suitable handle diameter should be $19.7 \%$ of the hand length [11]. The handle shape should be an elliptical shape with a width and length ratio of $1: 1.25$ that can be used for the operation of push force and pull force [8].

- Handle length: the minimum handle length should be 100 to $125 \mathrm{~mm}$ [12]. The palm width of $95 \%$ of workers is less than $100 \mathrm{~mm}$ [7]. Moreover, the average of hand breadth for the males was $87 \mathrm{~mm}$, and that for the females was $78 \mathrm{~mm}[13]$.

\footnotetext{
${ }^{a}$ Corresponding author : catincar@gmail.com
} 
- Handle slope: the pistol-shaped handle should be tilted at $78^{\circ}$ [10]. Some studies found that users prefer a slightly curved hammer handle of $10^{\circ}$ to replace the straight grip [14]. A hammer handle can reduce wrist damage when it is tilted $20^{\circ}$ to $40^{\circ}$ [15]. For the hand tool with a normal linear handle, the grip central line and the forearm support shaft form a degree of $110^{\circ}$ [16].

The purpose of this study was used anthropometric measurements to develop a handles that fits human-hand and suitable for the most people. The findings can serve as references for the industry and hand tool designers in the design of handles.

\section{Methods}

\subsection{Hand anthropometric measurements}

Sixty adult participants ( 30 male, 30 female; mean age $=31.2 \mathrm{y} ; \mathrm{SD}=4.4 \mathrm{y}$ ) took part in the experiment. Hand anthropometric measurements were obtained with the participant's right-hand using a caliper.

\subsection{Definition of idealized gripping gesture}

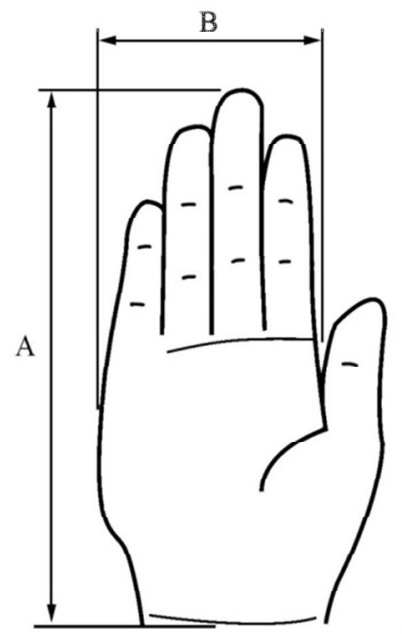

(a)

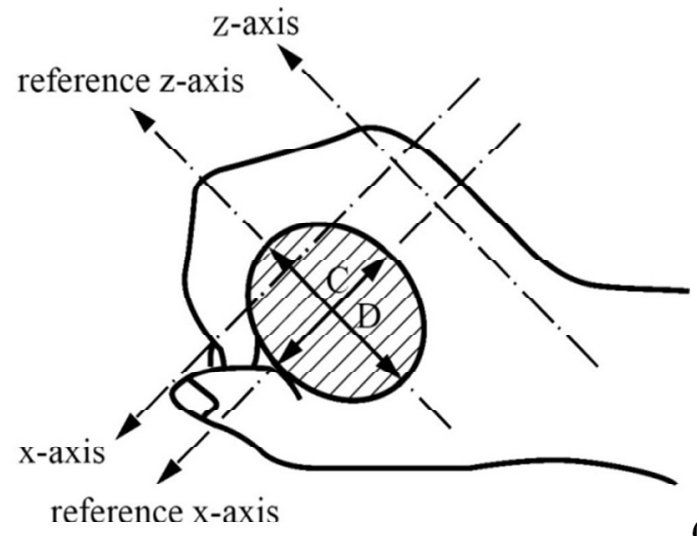

(b)

Figure 1. The definitions of the dimensional measurement of hand: (a) A, B, C, and D dimensions were measured with a caliper. (b) The grip gesture was determined by the biodynamic hand coordinate system defined in ISO 8727 [17].

Table 1. Definitions of hand measurements.

\begin{tabular}{|l|l|}
\hline item & definition \\
\hline A hand length & distance from top of the middle finger to the distal crease of the wrist. \\
\hline B hand breadth & maximum hand breath where the fingers join the palm. \\
\hline $\begin{array}{l}\text { C grip breath inside width } \\
\text { diameter }\end{array}$ & $\begin{array}{l}\text { inside hand elliptical diameter with the length of major axis measured at } \\
\text { grip breadth }\end{array}$ \\
\hline $\begin{array}{l}\text { D grip breath inside length } \\
\text { diameter }\end{array}$ & $\begin{array}{l}\text { inside hand elliptical diameter with the length of minor axis measured at } \\
\text { grip breadth }\end{array}$ \\
\hline
\end{tabular}

Figure 1 and Table 1 shows the definitions of the dimensional measurement of hand. The A-D dimensions were measured by using a caliper, as shown in the Fig.1a. In order to obtain the consistency of the gripping gesture, the palm and fingers of the hand needs to be position of the force distribution. The grip gesture were determined by the biodynamic hand coordinate system defined in 
ISO 8727 [17] is included in Fig. 1b. The z-axis is passes proximally through the third metacarpal bone when gripping gesture. The $\mathrm{x}$-axis of the system is approximately normal to the palm of the hand, projecting anteriorly from the origin when the hand lies open in the normal anatomical position, i.e. palms facing forward. The axis parallel to the $\mathrm{x}$ and $\mathrm{z}$-axis and passing through the center of the handle circle were used as the reference $\mathrm{x}$ and z-axis.

\section{Results and discussions}

\subsection{Hand anthropometric data}

Table 2 presents the results of anthropometric data. The overall means of hand length was $177.9 \mathrm{~mm}$ (187.9mm for males and $167.9 \mathrm{~mm}$ for females). In addition, the average of hand breadth (four fingers) was $79.4 \mathrm{~mm}(83.6 \mathrm{~mm}$ for males and $75.2 \mathrm{~mm}$ for females). The measurement results of hand in the current study were close to the anthropometric measurements of Taiwanese aged between 25 to 34 years old [18], suggesting that the anthropometric data in the present study can represent a design reference for related tool manufacturing industries in Taiwan.

Table 2. The results of hand dimensions (unit: $\mathrm{mm}$ ) (standard deviation of the mean in parentheses).

\begin{tabular}{|l|l|cc|c|}
\hline \multicolumn{2}{|l|}{ item } & \multicolumn{2}{|c|}{ This study } & Wang et al. (2002) \\
\hline \multirow{4}{*}{ male } & A hand length & 187.9 & $(7.9)$ & 183 \\
\cline { 2 - 5 } & B hand breadth (four fingers) & 83.6 & $(4.8)$ & 86 \\
\cline { 2 - 5 } & C grip breath inside width diameter & 44.5 & $(5.3)$ & - \\
\cline { 2 - 5 } & D grip breath inside length diameter & 35.6 & $(4.9)$ & - \\
\hline \multirow{4}{*}{ female } & A hand length & 167.9 & $(6.6)$ & 167 \\
\cline { 2 - 5 } & B hand breadth (four fingers) & 75.2 & $(6.2)$ & 75 \\
\cline { 2 - 5 } & C grip breath inside width diameter & 32.2 & $(4.5)$ & - \\
\cline { 2 - 5 } & D grip breath inside length diameter & 25.7 & $(5.0)$ & - \\
\hline \multirow{4}{*}{ all } & A hand length & 177.9 & $(12.4)$ & 175 \\
\cline { 2 - 5 } & B hand breadth (four fingers) & 79.4 & $(6.9)$ & 80.5 \\
\cline { 2 - 5 } & C grip breath inside width diameter & 38.3 & $(7.9)$ & - \\
\cline { 2 - 5 } & D grip breath inside length diameter & 30.7 & $(7.0)$ & - \\
\hline
\end{tabular}

\subsection{Handle length}

The handle length was determined by the hand breadth. In the current study, the result of hand breadth (four fingers) was consistent with the findings which suggested that approximately $95 \%$ of workers were below $100 \mathrm{~mm}$ [7]. According to the result of hand breadth, this study therefore considered that the handle length at least should be $100 \mathrm{~mm}$. Moreover, the average of hand breadth for the males of American was $87 \mathrm{~mm}$, and that for the females was $78 \mathrm{~mm}$ [13]. It was inferred that the hand breadth of Taiwanese was slightly shorter than that of American.

\subsection{Handle diameter}

Table 3. The ratio of major-to-minor diameter of handle dimensions.

\begin{tabular}{|l|c|c|}
\hline \multirow{2}{*}{ item } & \multicolumn{2}{|c|}{ handle diameter of elliptical grip* } \\
\cline { 2 - 3 } & This study & Cochran \& Riley (1986) \\
\hline male & $1: 1.25$ & - \\
\hline female & $1: 1.25$ & - \\
\hline all & $1: 1.25$ & $1: 1.25$ \\
\hline
\end{tabular}


Table 3 illustrates the results of handle diameters for males and females. The grip breath inside widthto-length diameter for all participants was 30.7 -to-38.3mm (35.6-to-44.5mm for males and 25.7-to$32.2 \mathrm{~mm}$ for females). The overall griping diameter of handle in the present study was consistent with the [5], which suggested that handle diameter should be in the range of 30 to $40 \mathrm{~mm}$. However, this suggested range of handle diameter was small for males, and large for females. Because of the hand length for females in the griping was smaller than for the males. Moreover, this study agreed the the diameter should be in a wider range of 25 to $50 \mathrm{~mm}$ [6]. It was more suitable for most people, but not clearly for the specific tool handle (i.e. power tool, peeler, or saw). No matter what a tool design should consider the different sizes of handle for different gender used.

\subsection{Handle cross-section}

The best cross-section of a handle for gripping was elliptical shape. The ratio of cross-section with width and length diameter for males and females were both 1: 1.25, as shown in the Table 3 . According to the [8] recommended that the ratio of width and length diameter was 1: 1.25 (28mm for the width diameter and $35 \mathrm{~mm}$ for the length diameter), suggesting that it is the best ratio for gripping. Moreover, a handle cross-section with the width-to-length diameter for gripping was 17.3 -to-21.5\% of the hand length (18-to-23.7\% for males and 15.3-to-19.2\% for females), as shown in the Table 4 . The overall results were close to the findings of [11], that the diameter of a suitable handle was $19.7 \%$ of hand length. However, this suggested value for a handle was large for females because their hand length was too small that did not enough to completely hold. Thus, a great size of handle cross-section should be depended on the hand length of users.

Table 4. The percentage of handle dimensions to hand length.

\begin{tabular}{|l|c|c|c|}
\hline \multirow{2}{*}{ item } & \multicolumn{2}{|c|}{ handle diameter } \\
\cline { 2 - 3 } & \multicolumn{2}{|c|}{ This study } & \multirow{2}{*}{ Kong \& Lowe (2005) } \\
\cline { 2 - 3 } & width diameter $^{*}$ & length diameter & \\
\hline male & $18 \%$ & $23.7 \%$ & - \\
\hline female & $15.3 \%$ & $19.2 \%$ & - \\
\hline all & $17.3 \%$ & $21.5 \%$ & $19.7 \%$ \\
\hline
\end{tabular}

* width diameter $=\mathrm{D}$ grip breath inside width diameter $/ \mathrm{A}$ hand length

${ }^{* * 1}$ ength diameter $=\mathrm{C}$ grip breath inside length diameter $/ \mathrm{A}$ hand length

\section{Conclusion}

This study presented a guideline for handle design based on hand anthropometric measurements. The findings in the current study are important for developing a comfortable tool handle to develop and manufacture a best shaped tool handle for users. Thus, our results could provide a handle reference for constructing a new tool handle design.

\section{References}

1. J. Marsot and L. Claudon, Design and ergonomics: methods for integrating ergonomics at hand tool design stage, International Journal of Occupational Safety and Ergonomics, 10 (1), 13-23 (2004)

2. P.G. Dempsey, R.W. McGorry, and N.V. O'Brien, The effect of work height, workpiece orientation, gender, and screwdriver type on productivity and wrist deviation, International Journal of Industrial Ergonomics, 33, 339-346 (2004)

3. L.F.M. Kuijt-Evers, J.W.R. Twisk, L. Groenesteijn, M.P.de Looze, and P. Vink, Identifying predictors of comfort and discomfort in using hand tools, Ergonomics, 48 (6), 692-702 (2005) 
4. L.F.M. Kuijt-Evers, T. Bosch, M.A. Huysmans, M.P.de Looze, and P. Vink, Association between objective and subjective measurements of comfort and discomfort in hand tools, Applied Ergonomics, 38, 643-654 (2007)

5. The Eastman Kodak Company, Kodak's Ergonomics Design for People at Work (Canada: John Wiley \& Sons, 2004)

6. A. Mital and W. Karwowski, Workspace, Equipment and Tool Design (Elsevier, Amsterdam, Netherlands, 1991)

7. V. Putz-Anderson, Cumulative Trauma Disorders: a Manual for Musculoskeletal Diseases of the Upper Limb (Taylor and Francis, London, England, 1988)

8. D. Cochran and M. Riley, An evaluation of knife handle guarding, Human Factors, 28 (3), 295301 (1986)

9. N.J. Seo and T.J. Armstrong, Effect of elliptical handle shape on grasping strategies, grip force distribution, and twisting ability, Ergonomics 54 (10), 961-970 (2011)

10. T. Fraser, Ergonomics Principles in the Design of Hand Tools: Occupational Safety and Health Series (International Labour Office, Geneva, Switzerland, 1980)

11. Y.K. Kong and B.D. Lowe, Optimal cylindrical handle diameter for grip force tasks, International Journal of Industrial Ergonomics, 35, $495-507$ (2005)

12. S. Konz, Work Design: Industrial Ergonomics (Grid Publishing Inc, Columbus, OH, 1983)

13. A.R. Tilley, The Measure of Man and Woman: Human Factors in Design (Henry Dreyfuss Associates, Wiley, New York, USA, 2002)

14. R. Krohn and S. Konz, Bent hammer handles, Proceedings of the Human Factors Society 26th Annual Metting, Santa Monica, CA: Human Factors Society, 413-417 (1982)

15. R. Schoenmarklin and W. Marras, Effects of handle angle and work orientation on hammering: II. Muscle fatigue and subjective ratings of body discomfort, Human Factors, 31 (4), 413-420 (1989)

16. K. Kroemer, H. Kroemer, and K. Kroemer-Elbert, Ergonomics: How to Design for Ease and Efficiency (Prentice Hall, Englewood Cliffs, NJ, 1994)

17. ISO 8727. Mechanical vibration and shock - human exposure -biodynamic coordinate systems, International Organization for Standardization, Geneva, Switzerland (1997)

18. M.J. Wang, M.Y. Wang, and Y.C. Lin, The Anthropometric Database Manual of Taiwan (Hsinchu: Ergonomics Society of Taiwan, 2002) 